\title{
Production and partial purification of membrane proteins using a liposome-supplemented wheat cell-free translation system
}

\author{
Akira Nozawa ${ }^{1,2}$, Tomio Ogasawara ${ }^{1,2}$, Satoko Matsunaga', Takahiro Iwasaki ${ }^{1}$, Tatsuya Sawasaki ${ }^{1,2,3^{*}}$ and \\ Yaeta Endo ${ }^{1,2,3 *}$
}

\begin{abstract}
Background: Recently, some groups have reported on cell-free synthesis of functional membrane proteins (MPs) in the presence of exogenous liposomes (liposomes). Previously, we reported synthesis of a functional AtPPT1 plant phosphate transporter that was associated with liposomes during translation. However, it is unclear whether or not lipid/MP complex formation is common to all types of MPs in the wheat cell-free system.

Results: AtPPT1 was synthesized using a wheat cell-free system with or without liposomes. AtPPT1 synthesized with liposomes showed high transport activity, but the activity of AtPPT1 synthesized without liposomes was less than $10 \%$ activity of that with liposomes. To test whether co-translational association with liposomes is observed in the synthesis of other MPs, we used 40 mammalian MPs having one to 14 transmembrane domains (TMDs) and five soluble proteins as a control. The association rate of all 40 MPs into liposomes was more than $40 \%$ (mean value: 59\%), while that of the five soluble proteins was less than 20\% (mean value: 12\%). There were no significant differences in association rate among MPs regardless of the number of TMDs and synthesis yield. These results indicate that the wheat cell-free system is a highly productive method for lipid/MP complex formation and is suitable for large-scale preparation. The liposome association of green fluorescent protein (GFP)-fusion MPs were also tested and recovered as lipid/MP complex after floatation by Accudenz density gradient ultracentrifugation (DGU). Employment of GFP-MPs revealed optimal condition for Accudenz floatation. Using the optimized Accudenz DGU condition, P2RX4/lipid complexes were partially purified and detected as a major band by Coomassie Brilliant Blue (CBB)-staining after SDS-PAGE.

Conclusion: Formation of lipid/AtPPT1 complex during the cell-free synthesis reaction is critical for synthesis of a functional MP. The lipid/MP complex during the translation was observed in all 40 MPs tested. At least 29 MPs, as judged by their higher productivity compared to GFP, might be suitable for a large-scale preparation. MPs synthesized by this method form lipid/MP complexes, which could be readily partially purified by Accudenz DGU. Wheat cell-free protein synthesis in the presence of liposomes will be a useful method for preparation of variety type of MPs.
\end{abstract}

\footnotetext{
* Correspondence: sawasaki@eng.ehime-u.ac.jp; yendo@eng.ehime-u.ac.jp ${ }^{1}$ Cell-Free Science and Technology Research Center and the Venture Business, Laboratory, Ehime University, 3 Bunkyo-Cho, Matsuyama, Ehime 790-8577, Japan

Full list of author information is available at the end of the article
} 


\section{Background}

MPs comprise up to $30 \%$ of genes in fully sequenced genomes and have critical roles in a variety of biological processes including signal transduction, substrate transport, and energy production [1,2]. However, functional and structural studies of MPs are far behind that of soluble proteins. One of the major bottlenecks in the study of MPs is the difficulty in obtaining sufficient amounts of homogeneous protein. For instance, it is typically not easy to purify MPs in preparative scale, due to their low abundance in natural sources. Overexpression of recombinant MPs in living cells is often unsuccessful due to the inhibitory effect of high MP concentration on host cell physiology [3].

Recently, cell-free protein synthesis systems have emerged as a promising tool for MP production [4-6]. In addition to decoupling protein production from the toxic or inhibitory effects on host cell physiology, cellfree systems offer a unique advantage in that protein synthesis can be easily modified by addition of accessory elements, such as detergents and lipids. The addition of detergents and lipids to cell-free systems allows the synthesis of MP/detergent and MP/lipid complexes, respectively, and successful synthesis of functional MPs in this fashion have been reported recently [7-11]. For example, Klammt et al. [12] demonstrated that a $\mathrm{G}$ protein-coupled receptor, ETB, can be synthesized in a soluble form using an Escherichia coli-based cell-free system supplemented with Brij78, and that the synthesized proteins have ligand binding activity. The ligand binding activity of a human olfactory receptor, hOR174 , synthesized using a wheat cell-free system in the presence of FC14, has been also reported [13]. Kalmbach et al. [14] reported that E. coli cell-free synthesized bacteriorhodopsin in the presence of liposomes was active in black lipid membrane mediated photocurrent measurements. Goren and Fox [15] showed reconstitution of the functional stearoyl Co-A desaturase complex, which consists of three proteins, cytochrome $b_{5}$, cytochrome $\mathrm{b}_{5}$ reductase, and human stearoyl-CoA desaturase 1 (hSCD1) synthesized by wheat cell-free system in the presence of asolectin liposomes. However, the general versatility of this method is unclear as the above examples focus on specific MPs.

In a previous study, we reported functional synthesis of a phosphate trranslocator in a wheat cell-free synthesis system supplemented with liposomes and formation of lipid/MP complexes [16]. The mechanism for production of functional protein in this method is not clear, but association of synthesized MP with liposomes may be an important step. To better understand this, we tested the timing of liposome addition to the cell-free MP synthesis reaction. We also investigated whether other MPs synthesized by the method also associates with liposomes. Moreover, we tried to purify the synthesized MP as a lipid/MP complex by DGU.

\section{Results and Discussion}

Timing of liposome-supplementation to wheat cell-free translation system for synthesis of functional MPs

Previously, we reported synthesis and liposome association of functional MPs using a wheat cell-free system supplemented with liposomes [16]. To verify that cotranslational association of MP with liposomes is critical for functional synthesis, we tested the synthesis of an Arabidopsis thaliana phosphate translocator, AtPPT1, in the presence of, absence of, and after post-translational addition of liposomes. These synthesized proteins were reconstituted into liposomes by freeze-thaw and sonication methods after mixing with substrate-preloaded liposomes and phosphate-incorporation activity was measured. Similar to a previous report [16], AtPPT1 synthesized in the absence of liposomes had only $4 \%$ of the activity of AtPPT1 synthesized in the presence of liposomes (Figure 1). AtPPT1 synthesized in the absence of liposomes was mixed post-translationally with liposomes and yielded $6 \%$ the activity of AtPPT 1 synthesized in the presence of liposomes. The association of synthesized AtPPT1 with liposomes, either co- or posttranslationally, was measured after sucrose DGU and

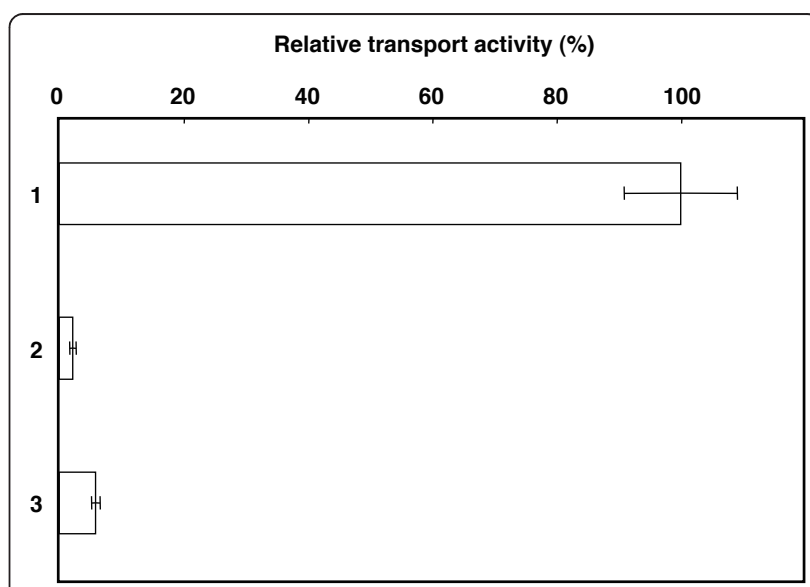

Figure 1 Effect of timing of liposome-supplementation on transport activity of synthesized AtPPT1. Three types of AtPPT1 proteins were prepared, 1: AtPPT1 synthesized with liposomes, 2: AtPPT1 synthesized without liposomes, 3: AtPPT1 synthesized without liposomes and mixed with liposomes post-synthesis. Each type of synthesis was reconstituted in liposomes that had been pre-loaded with $30 \mathrm{mM}$ phosphate. Uptake of $\left[{ }^{32} \mathrm{P}\right]$ phosphate into the liposomes was measured. The $100 \%$ exchange activity of the synthesized protein was $151 \mathrm{n} \mathrm{mol} / \mathrm{min} / \mathrm{mg}$ proteins. Data is reported as the mean $\pm \mathrm{SD}$ of values from three independent experiments. 
showed no significant differences (50\% co-translational, $62 \%$ post-translational). These results indicate that formation of lipid/AtPPT1 complex during the synthesis reaction is an important step for synthesizing functional AtPPT1. Supplementation of liposomes into the cell-free system would prevent aggregation and precipitation of AtPPT1 proteins during synthesis reaction. So, the constitution of AtPPT1/lipid complexes might be effective for formation of functional state MPs in the following freeze-thaw and sonication steps. For preparing MPs in functional state by cell-free system, preventing aggregation and precipitation of MPs during synthesis reaction by supplementation of lipids and/or detergents would be a critical point.

Cell-free synthesis of MPs in the presence of liposomes Using a wheat cell-free system in the presence of liposomes, a plant MP, AtPPT1, was synthesized as a lipid/MP complex (Figure 1). As MPs account for more than $50 \%$ of all human drug targets [17], we wanted to understand if the AtPPT1 membrane association described above was applicable to mammalian MPs. In general, MPs are classified by the number of TMDs and to start we tested five human MPs ranging from 2 to 12 TMD (KCNJ8, 2TMD; GABRD, 4TMD; HTR2B, 7TMD; P2RY11, 7TMD; SLC22A7, 12TMD). The selected mammalian MPs were synthesized in the wheat cell-free system in the presence of asolectin liposomes and their liposome association rates were measured after sucrose DGU. In this experiment, mRNA was prepared from fragments made by splitprimer PCR $[18,19]$. By using a PCR-based fragment as a template for in vitro transcription, time consuming steps, such as cloning of a target gene and construction of an expression vector were eliminated. Although the yield of template is low, this step allows for screening large numbers of proteins. As shown in Figure 2, every protein in the test set was associated with liposomes. After sucrose DGU, ${ }^{14} \mathrm{C}$-labeled proteins were predominantly detected in bands six to eight (Figure 2A), which corresponded with the observed liposome bands [16]. For each fraction, the radioactivity was measured and the relative amount of radioactivity for each fraction is depicted in Figure 2B. The extent of association for these proteins ranged from 52 to $73 \%$, when three fractions, numbers six to eight, were treated as liposome fractions. The observed MP association is similar to that seen AtPPT1 (58\%). Also there were no significant differences in the extent of association between the five MPs having two to 12 TMDs. These results suggest that association of synthesized MPs with liposomes during wheat cell-free synthesis is as likely to occur in other MPs as was observed for AtPPT1.
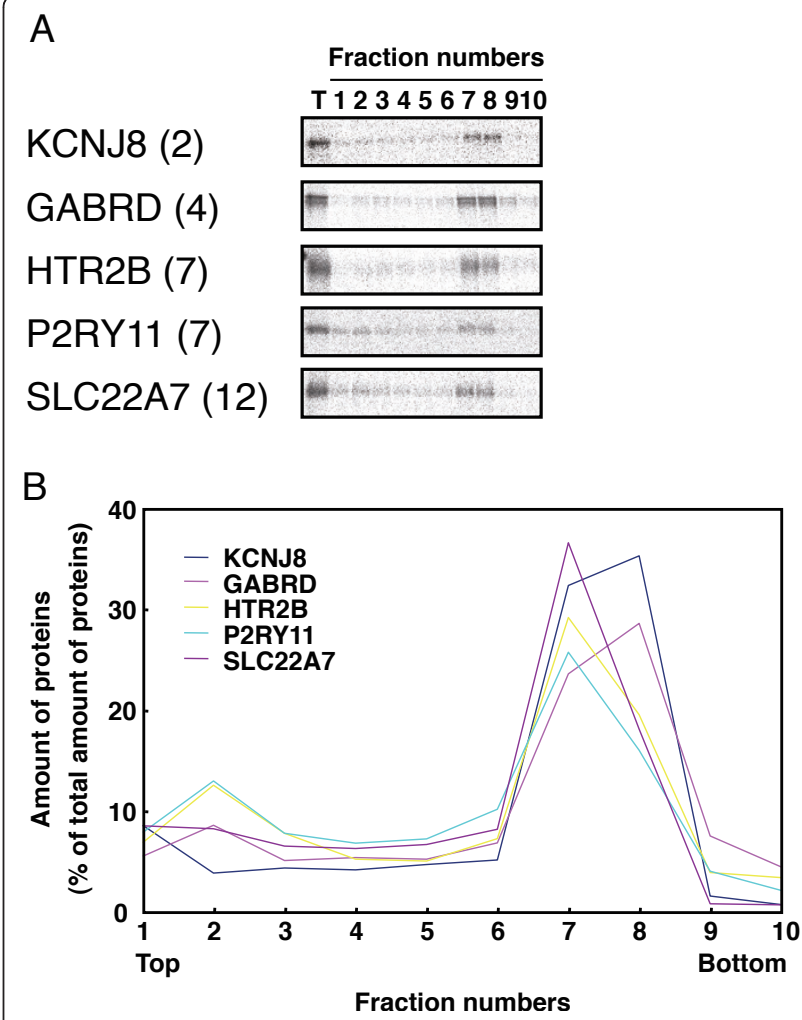

Figure 2 Association of synthesized MPs with liposomes.

(A) SDS-PAGE analysis of liposome association of MPs. MPs were synthesized using a wheat cell-free system supplemented with liposomes and $\left[{ }^{14} \mathrm{C}\right]$-leucine. After the synthesis reaction, the reaction mixture was subjected to sucrose DGU and fractions were collected from the top of the tube. Synthesized proteins in each fraction were detected by SDS-PAGE and autoradiography. The number of TMDs of each protein is shown in parentheses. T means total fraction of reaction mixture. (B) Yield of synthesized proteins in each fraction. After fractionation, synthesized proteins were precipitated by $10 \%$ trichloroacetic acid and radioactivity of each fraction was measured by liquid scintillation counter.

Next we further analyzed membrane association using a larger set of proteins, which consisted of 29 human and 6 mouse MPs. While a majority of the test proteins were chosen at random, we ensured that there were multiple representatives of each tested MP family to examine synthesis yield and extent of liposome association within a family. As shown in Figure 3A, the 29 MPs tested showed better synthesis efficiency than GFP (not shown, $4.4 \mu \mathrm{g} / 150 \mu \mathrm{L}$ reaction). The mean value of yield for the set of MPs was $5.9 \mu \mathrm{g} / 150 \mu \mathrm{L}$ reaction. All tested proteins belonging to $\mathrm{KCNJ}, \mathrm{P} 2 \mathrm{RX}, \mathrm{GABR}$ and SC5A families were well synthesized in the wheat cellfree system, whereas production of CACNG family proteins was very low (Figure $3 \mathrm{~B}$ and Table 1). The remaining proteins, belonging to ENDR, P2RY, SLC6A and SLC22A families had both poorly and well synthesized proteins. (Figure 3B and Table 1). 


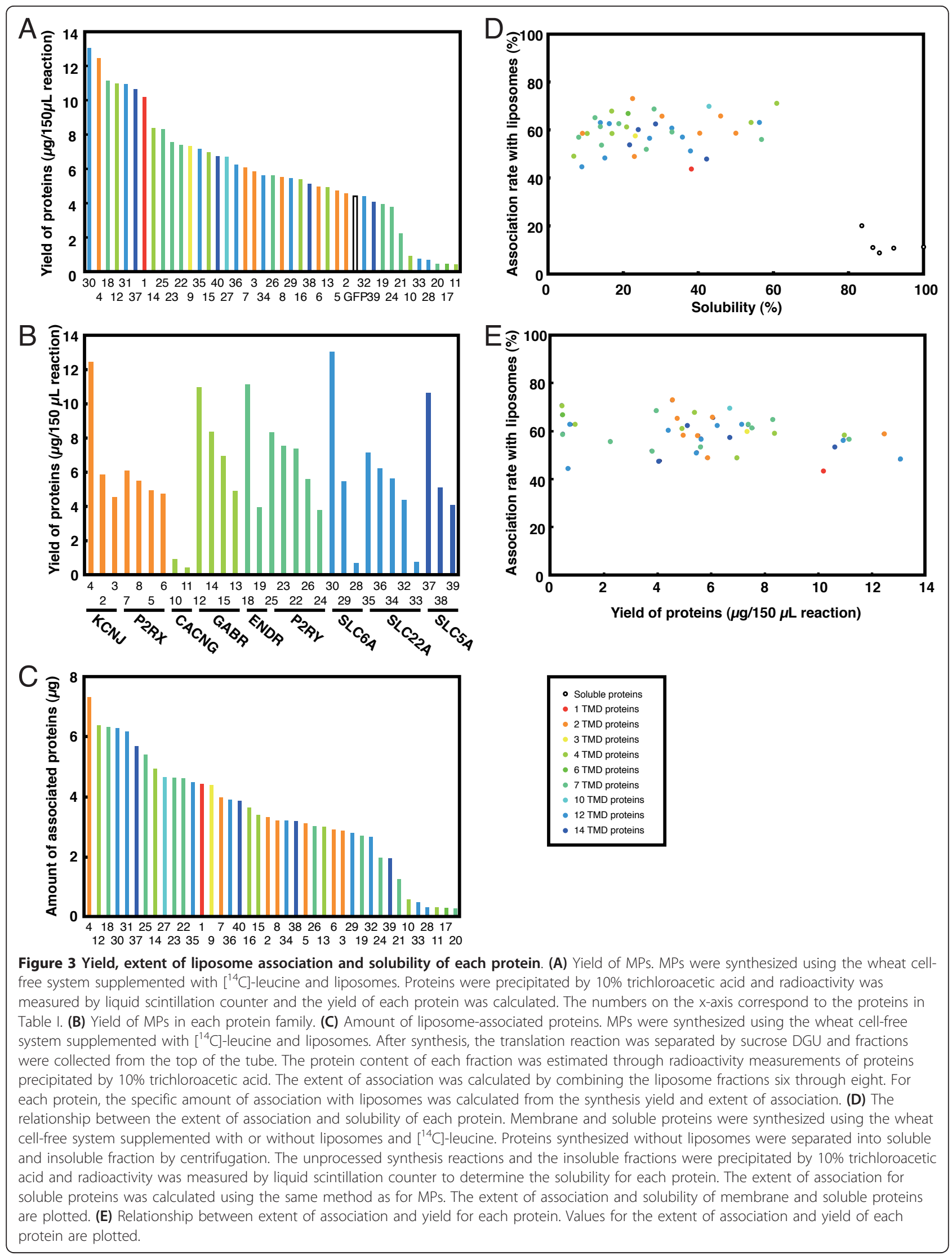


Table 1 Yield, association rate and solubility of synthesized membrane proteins

\begin{tabular}{|c|c|c|c|c|c|c|c|c|}
\hline & Proteins & Anotation & $\begin{array}{l}\text { Number } \\
\text { of TMD }\end{array}$ & $\begin{array}{c}\text { Molecular } \\
\text { weight }(\mathrm{kDa})\end{array}$ & $\begin{array}{l}\text { Yield ( } \mu \mathrm{g} / 150 \\
\mu \mathrm{l} \text { reaction) }\end{array}$ & $\begin{array}{l}\text { Solubility } \\
\text { (\%) }\end{array}$ & $\begin{array}{l}\text { Association rates } \\
\text { with liposomes (\%) }\end{array}$ & $\begin{array}{c}\text { Yield } \times \\
\text { Association } \\
\text { rates }(\mu \mathrm{g})\end{array}$ \\
\hline 1 & $\operatorname{ltga} 1^{\#}$ & Integrin & 1 & 131 & 10.2 & 38.3 & 43.3 & 4.4 \\
\hline 2 & KCNJ8 & $\begin{array}{c}\text { Potassium inwardly-rectifying } \\
\text { channel }\end{array}$ & 2 & 48 & 4.6 & 22.6 & 72.6 & 3.3 \\
\hline 3 & KCNJ13 & $\begin{array}{c}\text { Potassium inwardly-rectifying } \\
\text { channel }\end{array}$ & 2 & 41 & 5.9 & 23.1 & 48.7 & 2.9 \\
\hline 4 & KCNJ15 & $\begin{array}{c}\text { Potassium inwardly-rectifying } \\
\text { channel }\end{array}$ & 2 & 43 & 12.5 & 10.5 & 58.8 & 7.3 \\
\hline 5 & $\mathrm{P} 2 \mathrm{RX} 1$ & Purinergic receptor & 2 & 45 & 4.7 & 46.0 & 65.4 & 3.1 \\
\hline 6 & $\mathrm{P} 2 \mathrm{r} \times 2^{\#}$ & Purinergic receptor & 2 & 55 & 5.0 & 40.4 & 58.3 & 2.9 \\
\hline 7 & $\mathrm{P} 2 \mathrm{RX} 4$ & Purinergic receptor & 2 & 43 & 6.1 & 30.5 & 65.4 & 4.0 \\
\hline 8 & $\mathrm{P} 2 \mathrm{R} \times 5$ & Purinergic receptor & 2 & 47 & 5.5 & 50.0 & 58.2 & 3.2 \\
\hline 9 & GRIA2 & Glutamate receptor & 3 & 99 & 7.3 & 24.1 & 59.8 & 4.4 \\
\hline 10 & CACNG3 & $\begin{array}{l}\text { Voltage-dependent calcium } \\
\text { channel }\end{array}$ & 4 & 36 & 0.9 & 54.1 & 62.7 & 0.6 \\
\hline 11 & CACNG4 & $\begin{array}{l}\text { Voltage-dependent calcium } \\
\text { channel }\end{array}$ & 4 & 37 & 0.4 & 61.0 & 70.8 & 0.3 \\
\hline 12 & GABRA3 & GABA receptor & 4 & 55 & 11.0 & 17.1 & 58.1 & 6.4 \\
\hline 13 & GABRB1 & GABA receptor & 4 & 54 & 4.9 & 21.0 & 60.9 & 3.0 \\
\hline 14 & GABRD & GABA receptor & 4 & 51 & 8.4 & 12.5 & 58.8 & 4.9 \\
\hline 15 & GABRG1 & GABA receptor & 4 & 54 & 7.0 & 6.9 & 48.6 & 3.4 \\
\hline 16 & Glra1 $\#$ & Glycine receptor & 4 & 52 & 5.4 & 17.1 & 67.6 & 3.6 \\
\hline 17 & AQP3 & Aquaporin & 6 & 32 & 0.4 & 21.4 & 66.6 & 0.3 \\
\hline 18 & EDNRA & Endothelin receptor & 7 & 49 & 11.1 & 8.3 & 56.6 & 6.3 \\
\hline 19 & EDNRB & Endothelin receptor & 7 & 50 & 3.9 & 28.3 & 68.3 & 2.7 \\
\hline 20 & GPR37 & G protein-coupled receptor 37 & 7 & 67 & 0.5 & 33.0 & 58.8 & 0.3 \\
\hline 21 & HTR2B & 5-Hydroxytryptamine receptor & 7 & 54 & 2.2 & 57.0 & 55.8 & 1.2 \\
\hline 22 & P2RY2 & Purinergic receptor & 7 & 42 & 7.4 & 18.9 & 62.4 & 4.6 \\
\hline 23 & P2RY10 & Purinergic receptor & 7 & 39 & 7.5 & 14.0 & 61.2 & 4.6 \\
\hline 24 & P2RY11 & Purinergic receptor & 7 & 40 & 3.8 & 26.3 & 51.7 & 2.0 \\
\hline 25 & P2RY13 & Purinergic receptor & 7 & 38 & 8.3 & 12.7 & 64.8 & 5.4 \\
\hline 26 & P2RY14 & Purinergic receptor & 7 & 39 & 5.6 & 14.3 & 53.5 & 3.0 \\
\hline 27 & SLC1A7 & Glutamate transporter & 10 & 61 & 6.7 & 42.9 & 69.4 & 4.6 \\
\hline 28 & SLC6A3 & Dopamine transporter & 12 & 69 & 0.7 & 9.1 & 44.4 & 0.3 \\
\hline 29 & SLC6A13 & GABA transporter, GABA & 12 & 68 & 5.5 & 38.1 & 51.1 & 2.8 \\
\hline 30 & SLC6A18 & $\begin{array}{l}\text { Solute carrier family } 6 \text {, } \\
\text { member } 18\end{array}$ & 12 & 71 & 13.1 & 15.3 & 48.1 & 6.3 \\
\hline 31 & $\operatorname{Slc} 18 \mathrm{a} 2^{\#}$ & $\begin{array}{l}\text { Vesicular monoamine } \\
\text { transporter }\end{array}$ & 12 & 56 & 10.9 & 27.1 & 56.3 & 6.2 \\
\hline 32 & SLC22A4 & Organic cation transporter & 12 & 62 & 4.4 & 33.1 & 60.2 & 2.6 \\
\hline 33 & SLC22A7 & Organic anion transporter & 12 & 60 & 0.8 & 56.2 & 62.7 & 0.5 \\
\hline 34 & SLC22A8 & Organic anion transporter & 12 & 60 & 5.6 & 36.0 & 56.9 & 3.2 \\
\hline 35 & SLC22A11 & organic anion/cation transporter & 12 & 60 & 7.1 & 14.1 & 62.7 & 4.5 \\
\hline 36 & SLC22A12 & $\begin{array}{c}\text { Organic anion/cation } \\
\text { transporter }\end{array}$ & 12 & 60 & 6.2 & 16.4 & 62.3 & 3.9 \\
\hline 37 & Slc5a1 ${ }^{\#}$ & Sodium/glucose cotransporter & 14 & 73 & 10.6 & 21.8 & 53.4 & 5.7 \\
\hline 38 & SLC5A6 & $\begin{array}{c}\text { Sodium-dependent vitamin } \\
\text { transporter }\end{array}$ & 14 & 69 & 5.1 & 28.7 & 62.1 & 3.2 \\
\hline 39 & SLC5A10 & Sodium/glucose cotransporter & 14 & 62 & 4.1 & 42.2 & 47.5 & 1.9 \\
\hline 40 & Slc7a1 $1^{\#}$ & Cationic amino acid transporter & 14 & 67 & 6.7 & 23.3 & 57.3 & 3.8 \\
\hline
\end{tabular}

\footnotetext{
\# Mouse clone.
} 
The extent of association of all 40 proteins tested, containing between one and 14 TMDs, were from 43 to $73 \%$ and the mean value was $59 \%$ (Table 1 ). The amount of proteins associated with liposomes was calculated from the yield and extent of association for each protein (Figure $3 \mathrm{C}$ and Table 1 ). The mean value of the association yield was $3.4 \mu \mathrm{g} / 150 \mu \mathrm{L}$ reaction. When analyzing association by the number of TMDs, the lowest extent of association was $43 \%$ for 1 TMD (Itga1), whereas the mean value of association for proteins having more than 2 TMDs was approximately 60\% (Table 1 ). These results indicate that efficiency of association of proteins having only 1TMD might be lower than that of proteins having more than 2TMD.

Figure 3D shows the relationship between solubility and association rate of tested proteins. Solubility of MPs synthesized using the wheat cell-free system in the absence of liposomes ranged from eight to $61 \%$. The extent of association of these proteins ranged from 40 to $70 \%$ regardless of their solubilities. On the other hand, soluble proteins showed more than $80 \%$ solubility and their association rates were less than $20 \%$, indicating that the extent of liposome association for soluble proteins is much lower than that of MPs. In comparison to the tested soluble proteins, the MPs examined had a wide variety of sizes, functional roles and topologies, and all of them appeared to be efficiently associated with liposomes during cell-free synthesis. Moreover, there were no significant relationship between the extent of protein association and their respective yields (Figure 3E).

In this experiment, we found that a variety of MPs make complexes with lipids during wheat cell-free synthesis in the presence of liposomes. It is not yet clear whether these MPs are integrated into liposomes or attached to surface of liposomes with their hydrophobic regions. For replying to this question, further experiments for evaluating function and/or structure of each synthesized MP are needed. However, as association of MPs with liposomes prevents aggregation and precipitation of synthesized MPs during synthesis reaction, formation of lipid/MP complex would be an important step for preparing MPs.

Katzen et al. [20] recently reported that insertion of EmrE into a discoidal membrane scaffold in correctly folded state during cell-free synthesis by analysis of binding activity of its substrate, tetraphenylphosphonium. Moritani et al. [21] demonstrated that connexin-43 synthesized by an E. coli cell-free system, PURE system containing minimum protein synthesis factors [22], in the presence of liposomes is directly integrated with a uniform orientation into liposome membrane. The connexin-43 synthesized into liposomes was shown to deliver a hydrophilic and bioactive oligo-peptide to cells through gap junctions [23]. They speculate that liposomes may have chaperone-like function because their system consists of only protein synthesis factors and liposomes [21]. Although it is still not clear any kinds of MPs can receive such a chaperone-like effect from liposomes, the addition of artificial membranes to cell-free reactions appears to be effective in synthesizing membrane-stabilized MPs.

\section{Partial purification of synthesized MPs by density- gradient ultracentrifugation}

In this study, we demonstrated that a variety of mammalian MPs are efficiently associated with liposomes during wheat cell-free synthesis supplemented with liposomes. Next, we tried to partially purify the synthesized lipid/MP complexes from the endogenous wheat germ proteins. For this experiment we used P2RX4 as a model protein, because both the yield $(6.1 \mu \mathrm{g})$ and extent of association (66\%) are very close to the mean value for both of these parameters in the full mammalian MP dataset above (5.9 $\mu \mathrm{g}$ and 59\%, respectively).

A GFP-P2RX4 fusion protein was synthesized using the wheat cell-free system supplemented with liposomes and the resultant lipid/MP complexes were subjected to Accudenz DGU. Accudenz is a non-toxic medium used for fractionation of proteins, organelles, and cells [15,24-26]. The wheat cell-free synthesis reaction was brought to $40 \%$ Accudenz by addition of an $80 \%$ Accudenz solution, placed at the bottom of an ultra-centrifugation tube, and overlaid with 35\% Accudenz solution, $30 \%$ Accudenz solution and DGU solution. It is expected that after Accudenz DGU, liposomes float to the top of the centrifuge tube owing to their low density $[15,24]$. As shown in Figure 4A, the fluorescence from GFP-P2RX4 fusion proteins was observed at the top of the gradient after Accudenz DGU, while the majority of the fluorescence from a soluble GFP control remained at the bottom. After fractionation, the fluorescence of each fraction was measured with a spectrofluorometer (excitation $480 \mathrm{~nm} /$ emission $510 \mathrm{~nm}$ ). High fluorescence intensity at the top fraction, associated with floated liposomes, was detected in GFP-P2RX4 sample synthesized by liposome supplemented wheat cell-free synthesis (Figure 4B). In the other samples, GFP synthesized with or without liposomes and GFP-P2RX4 synthesized without liposomes, fluorescence was mainly detected in the lower fractions (Figure 4B). The extent of association of GFP-P2RX4 in this experiment (66\%: Fraction 1 and 2) was similar to the association of P2RX4 calculated by sucrose DGU (66\%). Although we also tested association of P2RX2-GFP with liposomes with same procedure, there were no significant differences in association rate (data not shown).

Although fluorescence was seen at the top of the gradient in the soluble GFP control after Accudenz DGU 


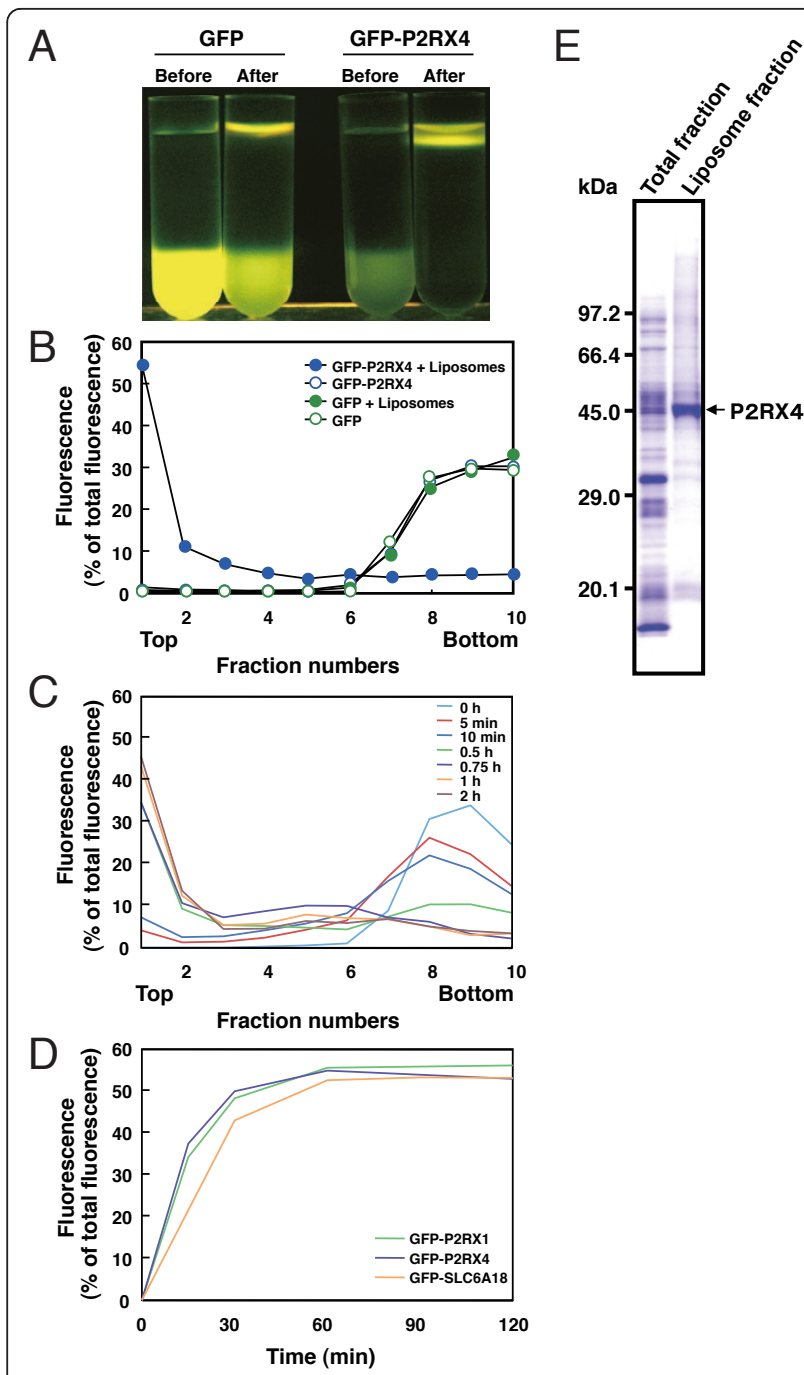

Figure 4 Partial purification of P2RX4 proteins by Accudenz DGU. (A) Floatation of GFP-P2RX4/lipid complex by Accudenz DGU. GFP and GFP-P2RX4 were synthesized using the wheat cell-free system supplemented with liposomes. After the synthesis reaction, the reaction mixture was subjected to Accudenz DGU. Fluorescence images were visualized using a transilluminator. (B) Yield of synthesized protein in each fraction. After DGU, fractions were collected from the top of the tube and the fluorescence intensity of each fraction was measured with a spectrofluorometer. (C) Effect of centrifugation time on floatation of lipid/MP complex. Synthesized GFP-fusion MPs were subjected to Accudenz DGU at varying centrifugation times. After DGU, fractions were collected from the top of the tube and the fluorescence intensity of each fraction was measured using a spectrofluorometer. (D) The effect of centrifugation time on the floatation of liposomes containing different MPs. GFP-P2RX4, -P2RX1, and -SLC6A18 fusion proteins were used in this experiment. Fraction No. one was treated as the liposome fraction and its fluorescence intensity in each condition was plotted. (E) Partial purification of P2RX4 proteins. P2RX4 was synthesized using the wheat cell-free system supplemented with liposomes. After the synthesis reaction, the reaction mixture was concentrated and subjected to Accudenz DGU. The synthesis mixture and the top lipid/MP complex fraction after DGU were applied to SDS-PAGE and stained by CBB. by using a transilluminator (excitation: $400-500 \mathrm{~nm}$ ) with a filter for removing blue light (Figure 4A), the fluorescence in the top fraction was not detected with a spectrofluorometer using a condition for detection of fluorescence from GFP (excitation $480 \mathrm{~nm} /$ emission 510 $\mathrm{nm}$ ) (Figure 4B). These results indicate that the fluorescence in the top fraction is not attributed to GFP but probably to the liposomes. In comparison to sucrose DGU, Accudenz DGU makes lipid/MP complex recovery easier due to the fact that liposomes float in Accudenz as opposed to sinking as in sucrose. Additionally, Accudenz is a preferred DGU solution because it is non-toxic.

The GFP-fusion P2RX4 is an ideal construct to determine the optimal conditions for Accudenz DGU as the liposome-associated protein can be readily monitored by fluorescence. We tested several centrifugation times for Accudenz DGU. As shown in Figure 4C, the fluorescence in the top fraction gradually increased in proportion centrifugation time. One-h centrifugation appears to be sufficient for lipid/MP complex floatation. The results from Accudenz DGU of two additional MPs, GFP-P2RX1 and GFP-SLC6A18, also showed that the floatation rates of lipid/MP complex plateaus at a one-h centrifugation (Figure 4D).

As shown in Figure 4B, GFP and GFP-P2RX4 could be clearly separated by DGU. The result suggests that lipid/ MP complexes can be separated from endogenous proteins derived from the wheat germ extract by Accudenz DGU. Nomura et al. also reported that cytochrome b5 synthesized by the wheat cell-free system in the presence of liposomes was easily purified by simplified discontinuous DGU [27]. In addition, Goren and Fox showed that a MP, hSCD1, synthesized by the wheat cell-free system supplemented with liposomes could be separated from endogenous wheat germ proteins by Accudenz DGU [15]. We next tried to purify P2RX4, without a GFP fusion, by this method. After synthesis supplemented with liposomes, lipid/MP complexes were concentrated by centrifugation and applied to Accudenz DGU. After ultracentrifugation, the top fraction was recovered and applied to SDS-PAGE. As shown in Figure 4E, P2RX4 was detected as a major band by CBB-staining after SDS-PAGE. This result indicates that lipid/MP complexes synthesized by our wheat cell-free system supplemented with liposomes can be partially purified by Accudenz DGU. To test whether proteins purified by this method are functional, we tested the activity of AtPPT1 partially purified as lipid/MP complexes. We detected transport activity of AtPPT1 purified with Accudenz DGU (data not shown). In addition to functional analysis, this partially purified protein could be used for structural analysis. However, some contaminating proteins from wheat germ extracts do 
float with the lipid/MP complexes. Goren and Fox [15] reported that, along with other unclassified contaminants, HSP70, elongation factor $1 \alpha$ and $16.9 \mathrm{kDa}$ heat shock protein were seen in wheat cell-free synthesized and floated lipid/MP complexes. For functional and structural analysis, further purification steps would be required including affinity-tag purification and gelfiltration.

\section{Conclusion}

We have developed a production method for lipid/MP complexes using a wheat germ cell-free system supplemented with liposomes. Using this method, a variety of mammalian MPs were efficiently associated with liposomes co-translationally. The resultant lipid/MP complexes are easily separated from other proteins in wheat germ extract by DGU. This synthesis method is useful in the preparation of MP for structural and functional analysis.

\section{Methods}

\section{Wheat Cell-free protein synthesis}

Details of the wheat cell-free reaction were described in previously [28-30]. The $40 \mathrm{MPs}$ and five soluble proteins in this study were selected from the Mammalian Gene Collection and FANTOM collection (Danaform, Yokohama, Japan). The unique primers for each protein (Additional file 1 Table S1) were designed and templates for transcription were made by the split-primer PCR method as described previously $[18,19]$. The first PCR was performed with $10 \mathrm{nM}$ of the gene specific primer (Additional file 1 Table S1) and $10 \mathrm{nM}$ of the AODA2303 primer (5'-GTCAGACCCCGTAGAAAAGA) or $10 \mathrm{nM}$ AODS primer (5'-TTTCTACGGGGTCTGACGCT). The second PCR was amplified with $100 \mathrm{nM}$ SPu primer (5'-GC GTAGCATTTAGGTGACACT), $1 \mathrm{nM}$ deSP6E01-S1 primer (5'-GGTGACACTATAGAACTCACCTATCTCC CCAACACCTAATAACATTCAAT CACTCTTTCCACTAACCACCTATCTACATCACCAACCACCCACCACCACCAATG), and $100 \mathrm{nM}$ AODA2303 primer or 100 nM AODS primer. mRNA was prepared by in vitro transcription in a reaction volume of $100 \mu \mathrm{l}$ and was purified by ethanol precipitation. The mRNA pellet was resuspended in $30 \mu \mathrm{l}$ of water. The translation reaction was performed using the bilayer method, supplemented with $\left[{ }^{14} \mathrm{C}\right.$-leucine $(50 \mu \mathrm{Ci} / \mathrm{ml}, \mathrm{GE}$ Healthcare, Tokyo, Japan $)$ [31], in which a $25 \mu \mathrm{l}$ translation layer was overlaid with a $125 \mu \mathrm{l}$ substrate feeding buffer. Asolectin liposomes were prepared as described previously [16,32] and added to both layers $(10 \mathrm{mg} / \mathrm{ml}$ final concentration). The bilayer reaction was incubated at $26^{\circ} \mathrm{C}$ for $16 \mathrm{~h}$. After the reaction, the amount of $\left[{ }^{14} \mathrm{C}\right]$-leucine incorporation into synthesized proteins, an indicator of synthesis yield, was determined by
$10 \%$ trichloroacetic acid precipitation and liquid scintillation spectroscopy.

\section{Sucrose density gradient ultracentrifugation}

Lipid/MP complexes were separated from proteins in the wheat germ extract by sucrose DGU. Synthesized proteins $(100 \mu \mathrm{l})$ were loaded onto a discontinuous sucrose gradient consisting of $1,300 \mu \mathrm{l}$ of $10 \%(\mathrm{w} / \mathrm{v})$ and $600 \mu \mathrm{l}$ of $30 \%(\mathrm{w} / \mathrm{v})$ sucrose in DGU solution containing $140 \mathrm{mM} \mathrm{NaCl}, 5.4 \mathrm{mM} \mathrm{KCl}$ and $10 \mathrm{mM}$ Tris- $\mathrm{HCl}$ (pH 8.0). The gradient was centrifuged at $105,000 \mathrm{~g}$ for $4 \mathrm{~h}$ at $4^{\circ} \mathrm{C}$ in a Hitachi S55S rotor (Hitachi High-Technology, Tokyo, Japan). Fractions were collected from the top of the tubes, and the protein content of each fraction was estimated by measurement of the amount of radioactivity associated with proteins precipitated by $10 \%$ trichloroacetic acid.

\section{Transport assay of phosphate translocator}

Liposomes were prepared from acetone-washed asolectin (Sigma-Aldrich, Tokyo, Japan) by sonication for $5 \mathrm{~min}$ at $4^{\circ} \mathrm{C}$ in water. AtPPT 1 was synthesized by wheat cell-free system with $(10 \mathrm{mg} / \mathrm{ml}$ final concentration) or without liposomes. Half of the AtPPT1 synthesized without liposomes was mixed with liposomes (10 $\mathrm{mg} / \mathrm{ml}$ final concentration) after the synthesis reaction and incubated for $30 \mathrm{~min}$ at $26^{\circ} \mathrm{C}$. These reaction mixtures were desalted by gel filtration with a MicroSpin G-25 column (GE Healthcare) that had been equilibrated with $10 \mathrm{mM}$ Tricine- $\mathrm{KOH}$ (pH 7.6).

The amount of protein synthesized in the cell-free system was estimated from the incorporation of $\left[{ }^{14} \mathrm{C}\right]-$ leucine. After the reaction, the amount of $\left[{ }^{14} \mathrm{C}\right]$-leucine incorporation into synthesized proteins, an indicator of synthesis yield, was determined by $10 \%$ trichloroacetic acid precipitation and liquid scintillation spectroscopy.

Substrate-including liposomes $(80 \mathrm{mg} / \mathrm{ml}$ final concentration) were prepared from acetone-washed asolectin by sonication for $5 \mathrm{~min}$ at $4^{\circ} \mathrm{C}$ in a solution containing $200 \mathrm{mM}$ Tricine- $\mathrm{KOH}$ (pH 7.6), $40 \mathrm{mM}$ potassium gluconate and $60 \mathrm{mM}$ potassium phosphate (substrate). Desalted reaction mixtures were mixed with the substrate-preloaded liposomes, frozen in liquid nitrogen, thawed at room temperature and sonicated for $18 \mathrm{sec}$. Substrate that remained outside of the liposomes was removed with a Dowex AG-1X8 column (Bio-Rad, Tokyo, Japan) that had been equilibrated with a solution containing $100 \mathrm{mM}$ sodium gluconate, $40 \mathrm{mM}$ potassium gluconate and $10 \mathrm{mM}$ Tricine- $\mathrm{KOH}(\mathrm{pH}$ 7.6). The liposome mixture was applied to the column and eluted with the equilibration solution.

Transport reactions were initiated by the addition of $13 \mu \mathrm{l}$ of $\left[{ }^{32} \mathrm{P}\right] \mathrm{Pi}$ (GE healthcare) to $300 \mu \mathrm{l}$ of liposomes 
(final phosphate concentration, inside: $30 \mathrm{mM}$, outside: $0.5 \mathrm{mM}$ ). The assay was performed at $25^{\circ} \mathrm{C}$ for $2 \mathrm{~min}$, and the reaction was terminated by application of the reaction mixture to a Dowex AG-1X8 column that had been equilibrated with $150 \mathrm{mM}$ sodium acetate. The radio-activity associated with the eluted liposomes was measured with a liquid scintillation spectrometer.

\section{Plasmid construction}

GFP fragments were amplified by PCR with the primers EcoRV-GFP-5' (5'-GAGAGATATCATGGGCCTGAACGACATCTTCGAGGCCCAGAAGATCGAG TGGCACGAAGGTGGAGGTGGAATGGTGAGCAAGGGCGA GGA-3') and GFP-NotI-3' (5'-TCTCGCGGCCGCTC CACCTCCACCCTTGTACAGCTCGTCCATGC-3).

The PCR fragments were digested with EcoRV and NotI and then cloned into the corresponding sites in the pEU-E01-MCS vector (Cellfree Sciences, Matsuyama, Japan). The resultant plasmid was designated pEU-E01GFP-N. P2RX4, P2RX1, and SLC6A18 were obtained from cDNA clones and amplified by PCR with the primer sets NotI-P2RX4-5' (5'-GAGAGCGGCCGCTGAAA ACCTGTATTTTCAGGGCATGGCGGGCTGCTGC GCCGC) and P2RX4-SalI-3' (5'-AGAGGTCGACTCACTGGTCCAGCTCACTAG), NotI-P2RX1-5' (5' GAGAGCGGCCGCTGAAAACCTGTATTTTCAGGGCATGGCGGGCTGCTGC GCCGC) and P2RX1-SalI-3' (5'-AGAGGTCGACTCACTGGTCCAGCTCACTAG), and NotI-SLC6A18-5' (5'-GAGAGCGGCCGCTGAAA ACCTGTATTTTCAGGGCATGGCTCATGCCCCA GAACC) and SLC6A18-SalI-3' (5'-AGAGGTCGACTCAGCGCATGTCCGTGTCCG), respectively. These PCR fragments were digested with NotI and SalI and then cloned into the NotI-SalI sites of pEU-E01-GFP-N. The resultant plasmids were designated pUE-E01-GFPP2RX4, pUE-E01-GFP-P2RX1, and pUE-E01-GFPSLC6A18, respectively, and used for production of GFPfusion proteins. The P2RX4 ORF was amplified by PCR using the primer pair P2RX4-EcoRV-5' (5'-GAGAGATATCATGGCGGGCTGCTGCGCCGC) and P2RX4NotI-3' (5'-CTCTGCGGCCGCTCCACCTCCACCCT GG CCAGCTCACTAGCAA). The PCR product was digested with EcoRV and NotI and then inserted into EcoRV-NotI sites of pEU-E01-MCS. The resultant plasmid was designated pEU-E01-P2RX4. The nucleotide sequences of each DNA fragment amplified by PCR was confirmed by DNA sequencing.

\section{Detection and quantification of fluorescence from GFP proteins}

Fluorescence images were visualized with a transilluminator (excitation: 400-500 nm, Dark Reader DR45M, Clare Chemical Research, Dolores, CO). Fluorescence intensity from GFP proteins was measured by a, Wallac 1420 Multilabel Counter spectrofluorometer (PerkinElmer Japan, Chiba, Japan).

\section{Partial purification of P2RX4}

mRNA was prepared by in vitro transcription using pEU-E01-P2RX4 as the template. The translation reaction was performed in the presence of liposomes (10 $\mathrm{mg} / \mathrm{ml}$ final concentration) using the bilayer method with a bottom layer of $500 \mu \mathrm{l}$ and an upper layer of $5500 \mu \mathrm{l}$. After the synthesis reaction, the reaction mixture was concentrated to $300 \mu \mathrm{l}$ with a concentrator (Amicon Ultra-15, 30,000 MWCO, Millipore-Japan, Tokyo, Japan). For Accudenz (Accurate Chemical and Scientific, Westbury, NY) DGU, Accudenz was dissolved into DGU solution to make 30, 35, and 80\% (w/v) Accudenz solutions. Three hundred $\mu \mathrm{l}$ of concentrated sample was mixed with $300 \mu \mathrm{l}$ of $80 \%$ (w/v) Accudenz solution. The resultant $40 \%$ Accudenz solution containing the synthesized protein was placed in the bottom of a centrifuge tube, and overlaid with $650 \mu \mathrm{l}$ of $35 \%(\mathrm{w} / \mathrm{v})$ Accudenz solution, $650 \mu \mathrm{l}$ of $30 \%$ (w/v) Accudenz solution, and $100 \mu \mathrm{l}$ of DGU solution. The gradient was centrifuged at $105,000 \mathrm{~g}$ for $4 \mathrm{~h}$ at $4^{\circ} \mathrm{C}$ in a Hitachi S55S rotor (Hitachi High-Technology, Tokyo, Japan).

\section{Additional material}

Additional file 1: Table S1

\section{Abbreviations}

CBB: Coomassie Brilliant Blue; DGU: density gradient ultracentrifugation; hSCD1: human stearoyl-CoA desaturase 1; Liposomes: exogenous liposomes; MP: membrane protein; PCR: polymerase chain reaction; SDS-PAGE: sodium dodecyl sulfate-polyacrylamide gel electrophoresis; TMD: transmembrane domain

\section{Acknowledgements}

We greatly thank Naoki Nakagawa and Kohei Matsuda for technical assistances and Michael Andy Goren for proofreading this manuscript. This work was supported by the Special Coordination Funds for Promoting Science and Technology by the Ministry of Education, Culture, Sports, Science and Technology, Japan (YE and TS).

\section{Author details}

${ }^{1}$ Cell-Free Science and Technology Research Center and the Venture Business, Laboratory, Ehime University, 3 Bunkyo-Cho, Matsuyama, Ehime 790-8577, Japan. ${ }^{2}$ RIKEN Systems and Structural Biology Center, 1-7-22 Suehiro-cho, Tsurumi-ku, Yokohama, Kanagawa 230-0045, Japan. ${ }^{3}$ ProteoMedicine Research Center, Ehime University, Toon, Ehime 791-0295, Japan.

\section{Authors' contributions}

YE and TS designed the experiment. AN, TO, SM, and TI performed the experiments.AN and TS wrote the manuscript. All authors read and approved the final manuscript.

Received: 29 October 2010 Accepted: 11 April 2011

Published: 11 April 2011 


\section{References}

1. International Human Genome Sequencing Consortium: Initial sequencing and analysis of the human genome. Nature 2001, 409:860-921.

2. Arabidopsis Genome Initiative: Analysis of the genome sequence of the flowering plant Arabidopsis thaliana. Nature 2000, 408:796-815.

3. Wagner $S$, Bader ML, Drew D, de Gier JW: Rationalizing membrane protein overexpression. Trends Biotechnol 2006, 24:364-371.

4. Ishihara G, Goto M, Saeki M, Ito K, Hori T, Kigawa T, Shirouzu M, Yokoyama S: Expression of $\mathrm{G}$ protein coupled receptors in a cell-free translational system using detergents and thioredoxin-fusion vectors. Protein Expr Purif 2005, 41:27-37.

5. Liguori L, Marques B, Villegas-Méndez A, Rothe R, Lenormand JL: Production of membrane proteins using cell-free expression systems. Expert Rev Proteomics 2007, 4:79-90.

6. Schwarz D, Dötsch V, Bernhard F: Production of membrane proteins using cell-free expression systems. Proteomics 2008, 8:3933-3946.

7. Berrier C, Park KH, Abes S, Bibonne A, Betton JM, Ghazi A: Cell-free synthesis of a functional ion channel in the absence of a membrane and in the presence of detergent. Biochemistry 2004, 43:12585-12591.

8. Liguori L, Marques B, Villegas-Méndez A, Rothe R, Lenormand JL: Liposomemediated delivery of pro-apoptotic therapeutic membrane proteins. $J$ Cont Rel 2008, 126:217-227.

9. Katzen F, Peterson TC, Kudlicki W: Membrane protein expression: no cells required. Trends Biotechnol 2009, 27:455-460

10. Shimono K, Goto M, Kikukawa T, Miyauchi S, Shirouzu M, Kamo N Yokoyama S: Production of functional bacteriorhodopsin by an Escherichia coli cell-free protein synthesis system supplemented with steroid detergent and lipid. Protein Sci 2009, 18:2160-2171.

11. Lim L, Linka M, Mullin KA, Weber AP, McFadden Gl: The carbon and energy sources of the non-photosynthetic plastid in the malaria parasite. FEBS Lett 2010, 584:549-554.

12. Klammt C, Schwarz D, Eifer N, Engel A, Piehler J, Haase W, Hahn S, Dötsch V, Bernhard F: Cell-free production of $\mathrm{G}$ protein-coupled receptors for functional and structural studies. J Struct Biol 2007, 158:482-493.

13. Kaiser L, Graveland-Bikker J, Steuerwald D, Vanberghem M, Herlihy K, Zhang S: Efficient cell-free production of olfactory receptors: detergent optimization, structure, and ligand binding analyses. Proc Natl Acad Sci USA 2008, 105:15726-15731.

14. Kalmbach $R$, Chizhov I, Schumacher MC, Friedrich $T$, Bamberg $E_{i}$ Engelhard M: Functional cell-free synthesis of a seven helix membrane protein: in situ insertion of bacteriorhodopsin into liposomes. $J \mathrm{Mol} \mathrm{BiO}$ 2007, 371:639-648

15. Goren MA, Fox BG: Wheat germ cell-free translation, purification, and assembly of a functional human stearoyl-CoA desaturase complex. Protein Expr Purif 2008, 62:171-178.

16. Nozawa A, Nanamiya H, Miyata T, Linka N, Endo Y, Weber AP, Tozawa Y: A cell-free translation and proteoliposome reconstitution system for functional analysis of plant solute transporters. Plant Cell Physiol 2007, 48:1815-1820

17. Klabunde T, Hessler G: Drug design strategies for targeting G-proteincoupled receptors. Chembiochem 2002, 3:928-944.

18. Sawasaki T, Ogasawara T, Morishita R, Endo $Y$ : A cell-free protein synthesis system for high-throughput proteomics. Proc Natl Acad Sci USA 2002, 99:14652-14657.

19. Sawasaki T, Gouda MD, Kawasaki T, Tsuboi T, Tozawa Y, Takai K, Endo Y: The wheat germ cell-free expression system: methods for highthroughput materialization of genetic information. Methods Mol Biol 2005, 310:131-144

20. Katzen F, Fletcher JE, Yang JP, Kang D, Peterson TC, Cappuccio JA, Blanchette CD, Sulchek T, Chromy BA, Hoeprich PD, Coleman MA Kudlicki W: Insertion of membrane proteins into discoidal membranes using a cell-free protein expression approach. J Prot Res 2008, 7:3535-3542.

21. Moritani $Y$, Nomura SM, Morita I, Akiyoshi K: Direct integration of cell-freesynthesized connexin-43 into liposomes and hemichannel formation. FEBS J 2010, 277:3343-3352.

22. Shimizu Y, Inoue A, Tomari Y, Suzuki T, Yokogawa T, Nishikawa K, Ueda T: Cell-free translation reconstituted with purified components. Nat Biotechnol 19:751-755.

23. Kaneda M, Nomura SM, Ichinose S, Kondo S, Nakahama K, Akiyoshi K Morita I: Direct formation of proteo-liposomes by in vitro synthesis and cellular cytosolic delivery with connexin-expressing liposomes. Biomaterials 2009, 30:3971-3977.

24. Sobrado P, Goren MA, James D, Amundson CK, Fox BG: A Protein Structure Initiative approach to expression, purification, and in situ delivery of human cytochrome b5 to membrane vesicles. Protein Expr Purif 2008, 58:229-241.

25. Graham JM, Ford T, Rickwood D: Isolation of the major subcellular organelles from liver using Nycodenz gradients without the use of an ultracentrifuge. Anal Biochem 1990, 187:318-323.

26. Sbracia M, Sayme N, Grasso J, Vigue L, Huszar G: Sperm function and choice of preparation media: comparison of Percoll and Accudenz discontinuous density gradients. J Androl 1996, 17:61-67.

27. Nomura SM, Kondoh S, Asayama W, Asada A, Nishikawa S, Akiyoshi K. Direct preparation of giant proteo-liposomes by in vitro membrane protein synthesis. J Biotechnol 2008, 133:190-195.

28. Madin K, Sawasaki T, Ogasawara T, Endo Y: A highly efficient and robustcell-free protein synthesis system prepared from wheat embryos: plants apparently contain a suicide system directed at ribosomes. Proc Natl Acad Sci USA 2000, 97:559-564

29. Takai K, Sawasaki T, Endo Y: Practical cell-free protein synthesis system using purified wheat embryos. Nature Protoc 2010, 5:227-238.

30. Goren MA, Nozawa A, Makino S, Wrobel RL, Fox BG: Cell-free translation of integral membrane proteins into unilamelar liposomes. Methods Enzymol 2009, 463:647-673

31. Sawasaki T, Hasegawa Y, Tsuchimochi M, Kamura N, Ogasawara T, Kuroita T, Endo $Y$ : A bilayer cell-free protein synthesis system for high-throughput screening of gene products. FEBS Lett 2002, 514:102-105.

32. Nozawa A, Nanamiya $H$, Tozawa Y: Production of membrane proteins through the wheat-germ cell-free technology. Methods Mol Biol 2010, 607:213-218

doi:10.1186/1472-6750-11-35

Cite this article as: Nozawa et al:: Production and partial purification of membrane proteins using a liposome-supplemented wheat cell-free translation system. BMC Biotechnology 2011 11:35.

\section{Submit your next manuscript to BioMed Central and take full advantage of:}

- Convenient online submission

- Thorough peer review

- No space constraints or color figure charges

- Immediate publication on acceptance

- Inclusion in PubMed, CAS, Scopus and Google Scholar

- Research which is freely available for redistribution 